\title{
Characterization of Polyurethane Nanocomposites for Flame Retardant Applications
}

\author{
Mena María Eugenia ${ }^{1,2}$, Torres Luis Adolfo ${ }^{3}$ and Estrada Rodolfo ${ }^{1}$ \\ 1. Department of Physics and Mathematics, University Iberoamericana Mexico City, Prolongación Paseo de Reforma \#880, Lomas \\ de Santa Fe, Mexico City, 01219, México \\ 2. Desarrollos y Acabados en Poliuretano S.A. de C.V., León, 37545, México
}

3.Department of Engineering, University Iberoamericana Leon, 37238, México

\begin{abstract}
In recent years, polymer nanocomposites have attracted extensive attention in materials science because they often exhibit a field of different properties from those of their counterpart polymer micro-composites whose matrices contain the same inorganic components. This novel polyurethane nanocomposite to reduce toxic gases was designed to improve the possibility to resolve several industrial and environmental problems after combustion as intoxication by inhalation. According to this, stoichiometry of rigid polyurethane foam was based on nonmetallic nanoparticles for fireproof applications. On the other hand, we realized synthesis and characterization for the novel polymer, Fourier Transform Infrared (FT-IR) spectroscopy and X-ray scattering were applied to collect information on the nanometer-scale physical structure of the polyurethane nanocomposite. Also, scanning electron microscopy (SEM) was used to understand the internal nanostructure before and after combustion, as well as the gas chromatography coupled system with thermal desorption analysis (GC/MSD), to identify the chemical compositions and compounds resulted by the combustion gases generated of the polyurethane nanocomposites foams that can produce toxicity. In addition, the mechanical and flammability properties of rigid polyurethane were evaluated according to international standard test methods of burning of polymer for example using test ASTM D635. According to this, polymer nanocomposites for flammability, not only improves the fireproof properties, but can also improve others properties as can be mechanical and thermal stability providing it the potential to bring true applications to materials to take advantage of the synergies in the polymer matrix. Based on this evidence, nanopolyurethane could be a new and functional polymer for construction, automotive, or textile industries.
\end{abstract}

Key words: Nanocomposite, polyurethane, flame retardant (FR), nanocharacterization, industrial applications.

\section{Introduction}

Nowadays, safety regulations are more strictly in industrial applications, it is the case for the fire safety regulations, these standards seek to contribute user's integrity. For a longtime, a great deal of effort has been invested in providing different materials with fireproof properties for wood, plastics, textiles, etc. Different types of approaches have been accepted and have been commonly used in various industries, such as electrical and electronics, building construction and transportation [1].

According with the United State Fire

Corresponding author: María Eugenia Mena Navarro, Ph.D., candidate, research field: engineering.
Administration (USFA), in 2014 on Unit States of America were reporting 1,298,000 fires, decreasing $22.7 \%$ since 2005; those events were causing of 3,275 deaths with $11.7 \%$ fewer demises than 2005 , as well as resulted of 15,775 injuries a reduction of 7.9\% during last 10 years. Economic losses were 11.6 billion dollars decreasing $21.0 \%$ since 2005 . In the United States approximately $75 \%$ of fire deaths occur at home. According with the statistics at home occurs the leading cause for fire injuries (78.0\%). However, residential fires do not cause more than $50 \%$ of the total fire property damage. Fires in large buildings and industry, while not causing a statistically significant number of deaths, are disproportionately high in cost. That is where we have to focus our attention [2]. 
Unfortunately, Mexico does not have statistics about how many fire events occur in the country, there are not official annual numbers which inform us about house fires, neither which are the causes of it. Mexican Association of Insurance Institutions said that the average material losses in the nation amount to almost \$165,000 Mexican pesos per claim. Michou and Mau Foundation, an organization dedicated to the assistance and prevention of Mexican children with severe burns, mentioned that electricity is the third cause of fires in Mexico.

Rigid polyurethane has a wide range of applications such as insulation, packaging, among others, due to its excellent properties. However, as many organic materials it is moderately flammable and the flame propagation is very fast, which increases the risk of fire, limiting its use in case of fire [3].

The main problem occurs with toxic gases expelled in combustion process, those harmful gases are the main cause of deaths, according with statistics, $80 \%$ of deaths are due to smoke and burn in the airway and not to body burns, in this context death by smoke inhalation is really fast [4]. On the other hand, some flame retardant (FR) additives are needed, among which halogenated compounds are the most widely used, and brominated additives are the main fire retardants. The combustion time of flame retarding polymer based on these retardants, halogen acids are evolved, people who would be exposed to these irritants could have potential corrosion damage. So much work has been done on halogen free [5].

Mechanical incorporation of FR additives into the bulk polymeric matrix is mostly low cost and fast blending technique. However, the loading of FR needed to be effective is usually too high, which can lead to a significant influence on the strength and elastic modulus of the materials [6, 7]. Moreover the microstructure, mechanical and thermal properties of polyurethane elastomers (PUs) are strongly dependent on the synthesis method employed to manufacture them [8]. In this context, nanoparticles could reduce the quantity used, and increase the mechanical and thermal properties.

Polymer nanocomposites, which are nanoparticles dispersed in a polymer matrix, have earned substantial academic and industrial interest since their inception [9]. Polymer nanocomposites for flammability applications are attractive because the formation of nanocomposite not only improves the fire properties, but can also improve other properties (e.g., mechanical properties), and it has the potential to bring true multifunctionality to materials [10]. Pholnak et al.'s [11] work analysis proposed ultraviolet-visible spectroscopy (UV-Vis) absorption on polyurethane coating filled with zinc oxide for economic large-scale production of composites.

In past years, the main flame retardants used have been halogenated additives to produce fireproof polymers. Because halogenated additives can release toxic gases in a fire, they have been gradually replaced by inorganic fillers, such as aluminum hydroxides, graphene oxides, and nanoclay particles, to reinforce the flame resistance of polymers [12-17]. Graphene oxides at high temperatures appear to have intumescent behaviors, and can generate a carbon rich protective char layer at the sample surface that shuts down the diffusion route of oxygen into the condensed phase, and ultimately, stops a fire from spreading [18-20]. Kim and Davis's [21] research as a part of the National Institute of Standards and Technology (NIST) had shown that carbon nanotubes can be used to create a coating which reduces the flammability of foam commonly used on upholstery by $35 \%$. However, CNTs also provide their FR effect in smaller concentrations compared to other fillers. An advantage of this nanomaterial is that they can increase the FR properties of a material, while at the same time enhance its material strength or provide an electrostatic discharge effect, because they will reduce their impact in the dry winter weather [21].

On MX 331874 patent Mena et al. [22] developed a novel polyurethane nanocomposite with multiwall 
carbon nanotubes to improve the dielectric resistance on the polymer. Wicklein et al. found that the porous structure of anisotropic foams based on nanocellulose and grapheme oxide improved thermal insulation properties [23].

Polyurethane layered nanocomposites, such as important classes of mineral reinforced thermoplastics, have been intensively investigated in the last decades as promising nanoengineered materials with achieved significant improved performances compared to originals [24]. Some researchers have been working on thermoplastic polyurethane (TPU) nanocomposites fire resistance, this property acted depending on the dispersion degree and nanomorphology of the nanoclays in the TPU matrix. According to Wang et al. [25] there have been some works on the effect of the microcellular structure of foams on the material's self-extinguishing performance in a fire, in order to understand better the interrelationship of fire resistance, microcellular structure, and nanoclay morphology with a microcellular structure of TPU. In addition, nanofiller dispersion in microcellular nanocomposite foams can be achieved using the molding injection microcellular reaction process with supercritical fluids as physical blowing agents [26-28].

Traditional non-intumescent FR contains halogens as chlorine, bromine, phosphorous, or inorganic metal compound, as the main FR component in the formulation, the presence of which usually helps to inhibit the flame spread via radical quenching and/or forming glassy protective layers instead of blown voluminous char during combustion [29, 30]. Extensive studies of inorganic nanoclay suggest that their FR mechanism, generates a thermal shielding clay layer at the material surface and exposes the nanocomposite to the flame, leading to a decrease in heat release and, ultimately, limiting material combustion [31]. Until now, numerous novel formulations of organic and inorganic additives based on phosphor, nitrogen, silica, and metals have been reported in literatures, while certain amount of studies for halogenated systems are still implicated. Those mentioned FR compounds may also contain blends of above mentioned elements for synergistic interaction [32]. Polyurethane contains nitrogen in its chemical composition caused by prepolymer used to react, thus in this case, there may also exist a phosphorous nitrogen synergistic effect during fire exposure [33]. Many formulations have been described that utilize components such as chlorinated paraffin's, antimony trioxide, and titanium dioxide for FR latex and alkyd based paints which, in case of fire hazard, help to reduce the flame spread in the gas phase and catalyze decomposition of the surface of the material to form non voluminous char in the condensed phase [34].

This paper is focused on the investigation of polyurethane nanocomposite to reduce toxins gases for fireproof applications. The influence of preparation procedure and addition of nonmetallic silica nanoparticles on phase and thermal behavior of synthesized rigid polyurethane was studied. Fourier transform infrared (FT-IR) spectroscopy and X-ray scattering were applied to collect information on the nanometer-scale physical structure of the polyurethane nanocomposite. Also, their morphological structures were compared with nanoparticles and without nanomaterials by scanning electron microscope (SEM) measurements to understand the internal nanostructure before and after combustion, as well as the gas chromatography system-mass spectrometry analyzes to identify the volatiles compounds resulted on combustion gases of the polyurethane (PU) nanocomposite foams also to understand if those materials can produce toxicity. The industrial sector has detected a market niche for rigid polyurethane nanocomposite to manufacture products with applications on the building industry; which could be used on the roof or on walls, as stone or wood imitation.

\section{Experimental Section}

Polyurethane nanocomposite was made by synthesis 
of several polyol's polyether and the isocyanate function along with the emergence of the urethane groups and allowed to react. Different samples were prepared in two groups, the control polyurethane without nanoparticles and polyurethane with silica oxide nanoparticles to create a specific stoichiometry for all raw materials. Also the polyurethane stoichiometry involved two different concentrations of silica oxide nanoparticles the first with $0.1 \mathrm{wt} \%$ and the other $1 \mathrm{wt} \%$ bases polyol system.

The experimental procedure was determinated by several steps. The polyurethane nanocomposite was evaluated and characterized by using X-ray diffraction (XRD), technical spectroscopy as FT-IR, analytical methods such as scanning electron microscopy (SEM) and gas chromatography system-mass spectrometry (GC/MSD). All this information helps to make the perfect stoichiometric polymer nanocomposite according to the customer requirements. In addition flammability tests were evaluated according to international methods of burning for example using test ASTM D635 titled standard test method for rate of burning and/or extent and time of burning of plastics in a horizontal position.

\subsection{Characterization of the Samples}

Polyurethane nanocomposites samples were characterized by different equipments and techniques. FT-IR spectroscopy with a Cary 670 FTIR-ATR spectrometer and XRD spectroscopy by equipment D2 PHASER were applied to collect information on the nanometer-scale physical structure of the polyurethane nanocomposite behavior on the silica nanoparticles dispersion degree. Also, SEM Jeol model JSM-7800F was used to understand the internal nanostructure before and after combustion as well as to evaluate the composition and the size of silica oxide nanoparticles. Gas chromatography coupled system with thermal desorption analysis was performed to identify the volatiles compounds resulted on the combustion time that can produce toxicity on the consumers.

\subsection{Materials}

The flexible polyol, Desmophen 101 from Covestro, which is a polyether polyol based Polyurethane, was used as the polymer matrix in this study. It is an oxide-based triol diol of propylene with special oxide modification of ethylene having an average molecular weight of 4,000. This polyol is used for manufacturing flexible foams, solid elastomers, microcellular and semirigid flexible foams. It hydroxyl group -OH numbers was $28 \mathrm{mgKOH} / \mathrm{g}$ with 800 (mPa॰s) of viscosity at $25{ }^{\circ} \mathrm{C}$. 1,4-butanediol (C4H10O2) was used as chain extender with molecular weight of 90.12 and specific gravity of $1.010 \mathrm{~g} / \mathrm{cm}^{3}$. A Fyrol PCF (Tris (2-chloroisopropyl) phosphate) is an additive FR with very good hydrolytic stability used extensively in rigid and flexible polyurethane foams, Phosphorus content $9.5 \mathrm{wt} \%$ and Chlorine content $32.5 \mathrm{wt} \%$. Its specific mass density was $1.29 \mathrm{~g} / \mathrm{cm}^{3}$, Fyrol PCF was used on minimum quantity as recommend, because it is the cheapest material and also very used on flexible foams. The objective was to use that additive in less percentage and mixed with nanoparticles to improve the reduction of toxic gases on PU nanocomposite, as well as to reduce the cost on the final product. Non-metallic nanoparticles are usually used as nanoscale filler for many plastics to improve their physical properties.

Isocyanate is an important component to produce polyurethane foam with versatile properties, for this study it was essential to use a polyether prepolymer to react with polyol system with nanoparticles. Mondur $\mathrm{PF}$ is a liquid MDI (modified 4,4'-diphenylmethanediisocyanate) prepolymer Isocyanate, from Covestro, to make foams, for microcellular polyurethane soles, integral skin and semi-flexible polyurethane foams.

It-NCO percentage weight was $23.1 \%$ with 800 (mPa $\bullet$ ) of viscosity at $25{ }^{\circ} \mathrm{C}$. Mondur PF is typically used in combination with high molecular weight, reactive polyether polyols in the manufacture of high performance flexible elastomers and specialty foams 
(integral skin and semi-flex). Its controlled functionality makes it particularly useful in the manufacture of polyurethane shoe soles and wheels/tires. Mondur PF also has utility in adhesive applications. Solids should form because of exposure to low temperatures, it may be possible to reliquify Mondur PF by heating. The temperature of the MDI should not exceed $60^{\circ} \mathrm{C}$ or $140{ }^{\circ} \mathrm{F}$.

\subsection{Preparation Process of Polyurethane Nanocomposite}

The preparation process to produce nanocomposite foams is described below. In the first step, raw material of PU and nanoparticles were prepared by stoichiometric blend. Materials with a variety of formulations on concentrations ( $0.1 \mathrm{wt} \%$ and $1 \mathrm{wt} \%)$ were made to have different samples. In this study, hexane was used as physical blowing agent on the process. Chain extender was put as the last component to the reaction system, mixed and degassed in order to remove residual bubbles. Process by reaction in-situ used to produce solid rigid polyurethane nanocomposite. Those samples were prepared to compare and to calculate correlations on their properties.

Experimental processing parameters value for the in situ reaction process polyurethane and polyurethane nanocomposite, were the follow: Machine return speed 6.20 minutes/cycle, mold temperature on $45^{\circ} \mathrm{C}$, cooling time at 13 seconds, isocyanate at $28{ }^{\circ} \mathrm{C}$, polyol system at $22{ }^{\circ} \mathrm{C}$, flow rate $6.67 \mathrm{gr} / \mathrm{s}$, injection pressure for isocyanate 20 pounds, injection pressure for polyol system 40 pounds.

\section{Results and Discussion}

\subsection{SEM}

The microcellular structures of the PU nanocomposite foams were observed using a SEM JSM-7800 F with an accelerating voltage of $10 \mathrm{kV}$. The SEM micrographs of the microcellular structures in the nanocomposite foams are shown in Fig. 1. It can be seen that the bubbles of the unfilled PUNSi foam presented a non uniform cell size and random distribution over the entire foam. SEM analysis supports the chemical composition and morphology identification. According to the experiment's results the specific characteristics of nanomaterials can be used to obtain better chemical, thermal and mechanical properties. The SEM micrograph of the post burned polyurethane nanocomposite foam is shown in Fig. 2. Compared to the microstructure of the original polyurethane nanocomposite foam, the bubbles in the unburned nanocomposite almost maintained their original microstructure and porous structure. However, polyurethane nanocomposite burned changed totally its nanostructure, only one

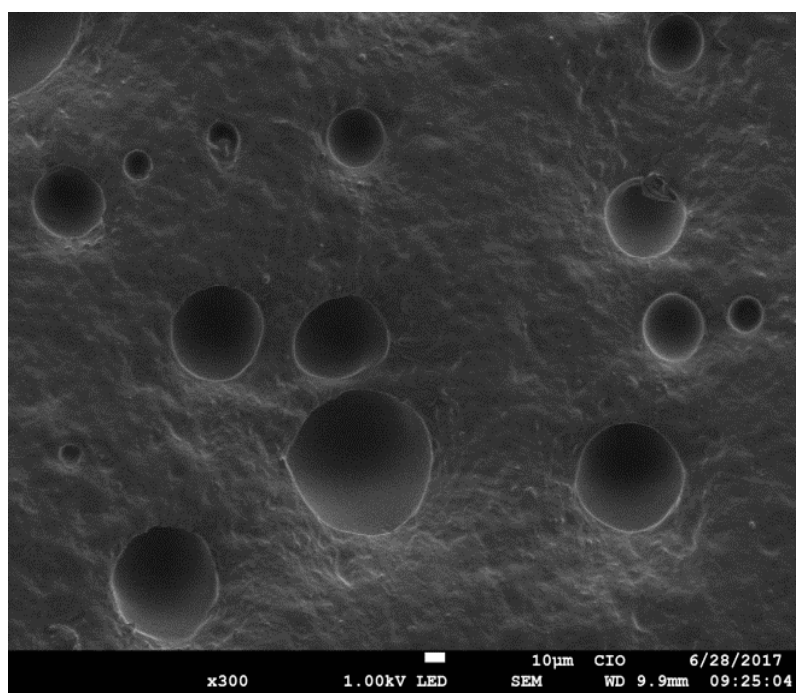

Fig. 1 Micrograph of top section morphology of unburned polyurethane nanocomposite with silica oxide nanoparticles.

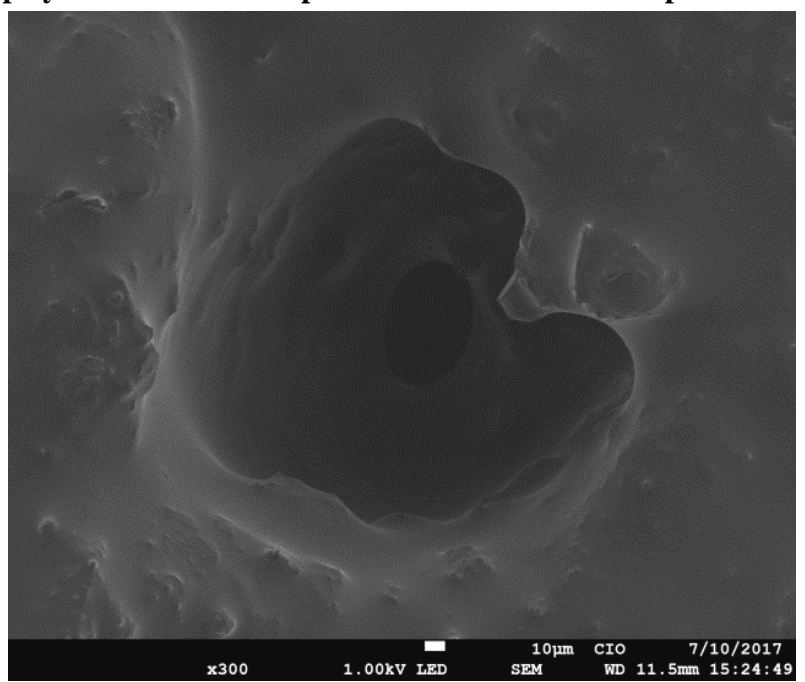

Fig. 2 Micrograph of top section morphology postburn polyurethane nanocomposite with silica oxide nanoparticles. 
pore can be seen, at the same micrograph area. An important part of the method was the characterization of the nanocomposite before ignition and after combustion.

\subsection{XRD Spectroscopy}

The effect of the material foaming behavior on the silica nanoparticles dispersion degree was investigated using XRD equipment D2 PHASER.

XRD analysis of nanocomposite silica-polyurethane is shown in Fig. 3, the samples are observed with different concentrations ( $1 \mathrm{wt} \%$ and $0.1 \mathrm{wt} \%$ ) above the control line of rigid polyurethane without silica oxide nanoparticles or additives. The differences between polyurethane nanocomposites are observed from the beginning but in the angle degree 2 theta from 13 to 23 , it is accentuated more; from 27 to 46 the sample with silica oxide nanoparticles is below the control, from angle 50 onwards behave similar.

\subsection{FT-IR Spectroscopy}

Infrared spectroscopy has been applied to the characterization of polyurethane nanocomposite. IR characterization can provide information about the chemical nature of polyurethane and the level of hydrogen bonding in the polymer. This is important because the level of phase separation in polyurethanes which affects their mechanical and thermal properties is related to the level of hydrogen bonding [35].

Measurements were performed at room temperature with a Cary 670 FTIR-ATR spectrometer. Single beam spectra of the samples were scanned them between 4,000 and $399 \mathrm{~cm}^{-1}$ with a resolution of $2 \mathrm{~cm}^{-1}$, in an absorbance mode. IR spectroscopy can distinguish between the MDI and polyether urethanes and identify the diols and polyether glycols used to prepare the polymers. The broad band at about $3,350 \mathrm{~cm}^{-1}$ is assigned to hydroxyl -OH group stretching frequency. The FT-IR spectra of polyurethane show broad bands around 3,253-3,396 $\mathrm{cm}^{-1}$ due to $>\mathrm{N}-\mathrm{H}$ bond. The bands around 1,541-1,551 $\mathrm{cm}^{-1}$ and 1,600-1,635 $\mathrm{cm}^{-1}$ confirm the presence of OCONH- groups. These spectra do not show hydroxyl group frequency due to the formation of OCONH- linkage, while terminal -NCO group frequency is obtained around 2,263-2,275 $\mathrm{cm}^{-1}$, which gives evidence of the structure of polyurethanes. Hydroxyl peak intensities are in correspondence with polyols hydroxyl numbers. Pavlicevic et al. [36]

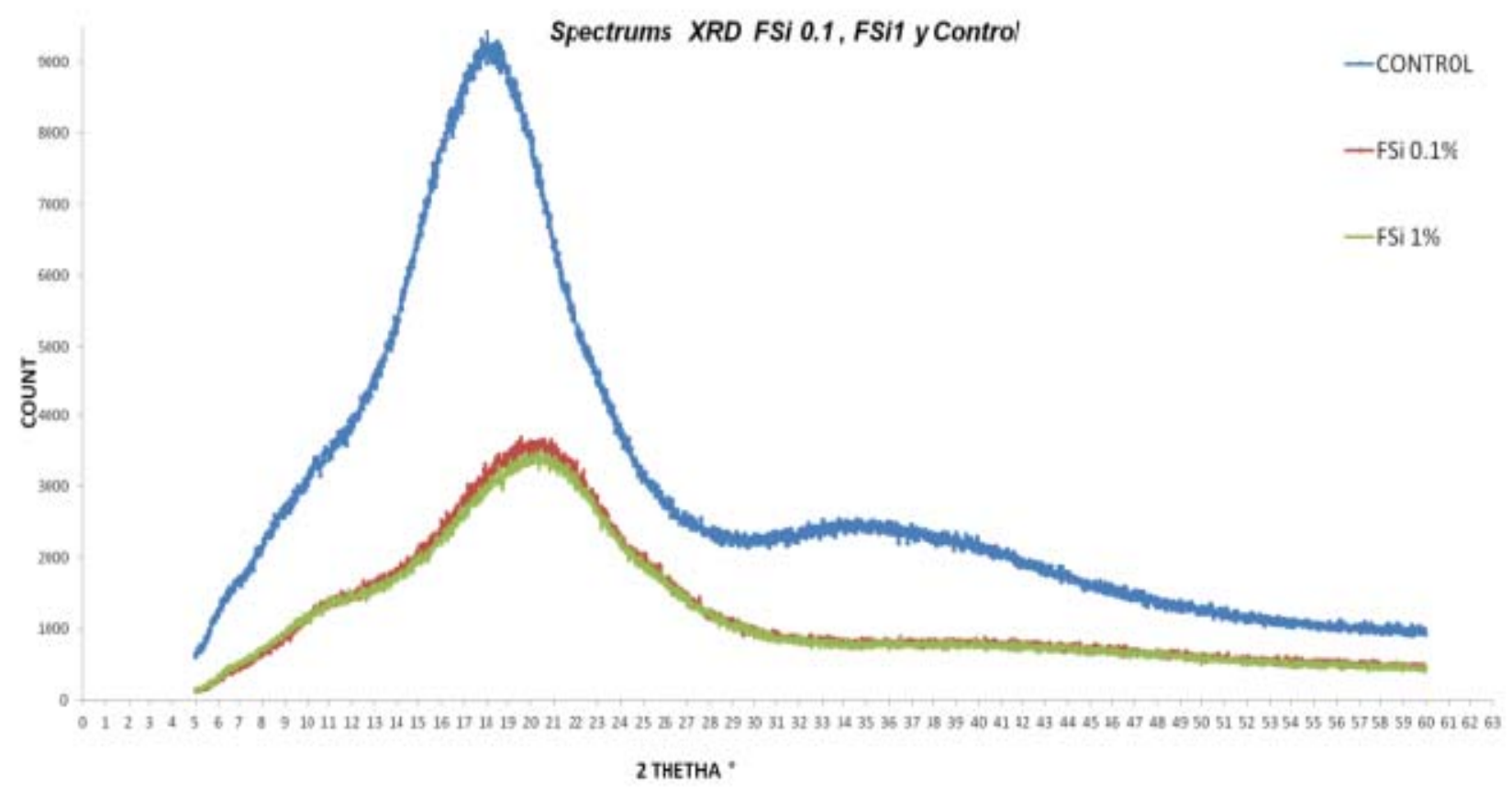

Fig. 3 Diffractogram of X-ray of nanocomposite of rigid polyurethane with silica oxide nanoparticles. 


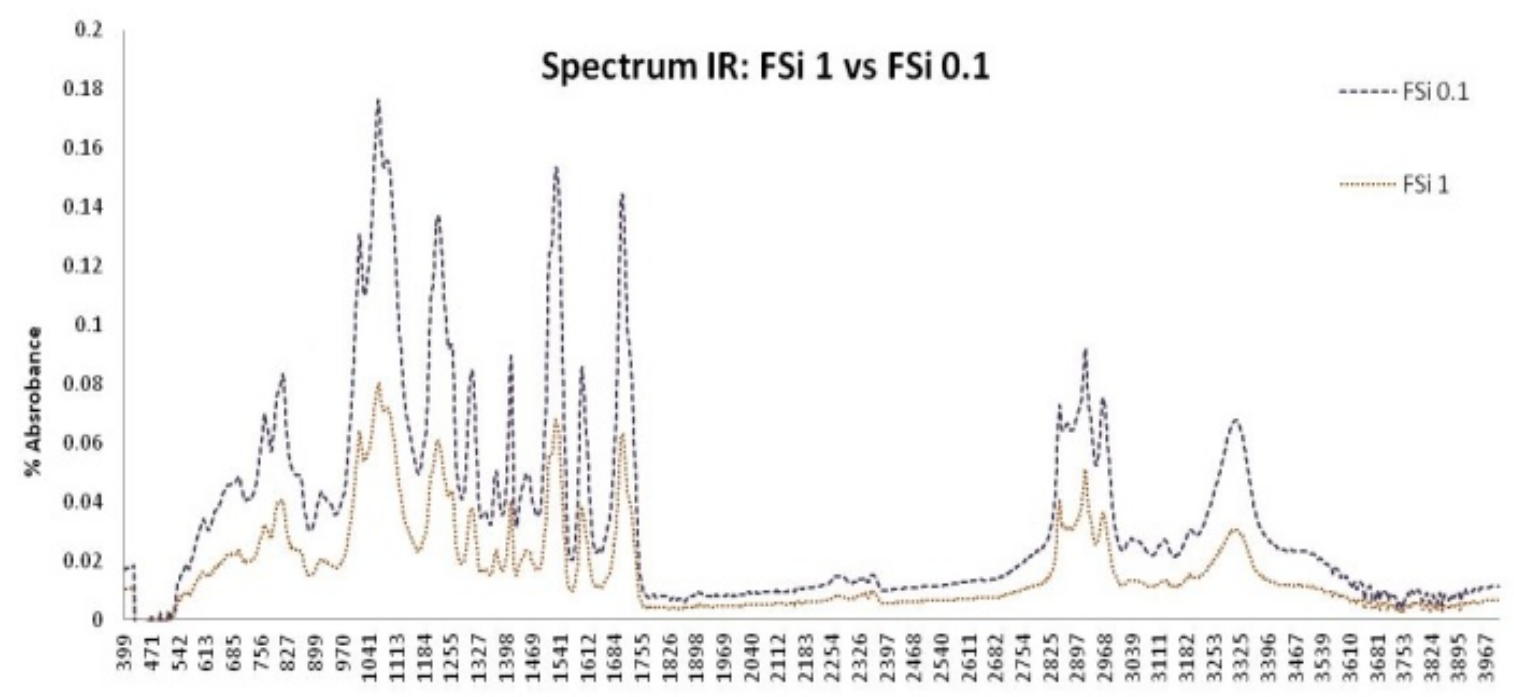

Wavenumbers $(\mathrm{cm} \cdot 1)$

Fig. 4 IR spectrum of nanocomposite of rigid polyurethane with silica oxide nanoparticles.

investigated a harp absorption peak positioned at 3,319 $\mathrm{cm}^{-1}$ that is connected to NH groups. The formation of hydrogen bonding due to the interaction between polyurethane and reinforced fillers was confirmed by deconvolution of -NH stretching and carbonyl group absorbance region of obtained IR spectra.

Fig. 4 shows the results of absorbance for samples with different concentrations of silica oxide nanoparticles. As can be observed, the highest line corresponds to the minimum concentration of $\mathrm{SiO}$ nanoparticles and present slightly absorbance percentage of the polyurethane nanocomposite. Significant differences between materials concentration are observed from the wavelength since 613 to $1,755 \mathrm{~cm}^{-1}$, as well as from 2,825 to $3,610 \mathrm{~cm}^{-1}$.

Therefore the specific characteristics of nanomaterials can be used to obtain better chemical, biological and mechanical properties. The efficient and effective uses of this allow proposing advanced industrial solutions. Polymeric materials are involved in most fires occurring in urban areas and transport, because they may begin the spread of fire.

\subsection{ASTM 635 Flammability Test}

The American Society for Testing and Materials (ASTM) has several flammability tests for polymers depending on their structure and their industrial applications, for example TPU, acrylonitrile butadiene styrene (ABS), polyurethane (PUR), polyamide (PA), polypropylene (PP) and others. The various flammability tests are all similar, first make the orientation of a test sample either horizontal or vertical and place it in a test chamber; second, apply a flame from a Bunsen Burner for a specified time; and third, measure the time or distance that the flame propagates. Those tests are mainly used for quality control, production control and material comparisons. It cannot be used as a criterion for fire hazard. Standards applicable to polyurethane can be ASTM D5132, ASTM D4986 or ASTM D635/ISO 3795 used for automotive industry [37-40]. The last norm was applied to evaluate using an Atlas horizontal flame chamber equipment certified for those proofs.

Flammability test ASTM D635 scope is used to determine the relative rate of burning of self supporting plastics. This test method was developed for polymeric materials used for parts in devices and appliances. The results are intended to serve as a preliminary indication of their acceptability with respect to flammability for a particular application. This standard is used to measure and describe the response of materials to heat and flame under controlled conditions, but does not by 
itself incorporate all factors required for fire hazards or fire risk assessment of materials, products, or assemblies under actual fire conditions.

These standard measures describe the response of materials to heat and flame under controlled conditions, but do not by itself incorporate all factors required for fire hazard or fire risk assessment of the materials, products, or assemblies under actual fire conditions. The methods include 3 specimens for every test; samples needed for the test is $125 \mathrm{~mm}$ of length, 130 $\mathrm{mm}$ of width and $10 \mathrm{~mm}$ of thickness. During 15 seconds it was exposed to a gas flame directed on the sample. After that, the distance and time of burning were observed to know if the flame in these samples was self-extinguishing or not. As shown in Table 1.

As a result of testing, rigid polyurethanes control were self-extinguishing, with a little bit of smoke but a lot of flame melt as shown in Fig. 5. In other hand, the results show that rigid polyurethane nanocomposites with dioxide silica after test were self-extinguishing; with a lot of smoke but a little bit of flame melt, in this case helps to reduce the spread of fire as shown in Fig. 6. Both nanocomposites could be dangerous if the material is used on high places because polyurethane nanocomposite melts during combustion and some drops, could fall on a flammable material, spreading the flame.
3.5 Gas Chromatography (GC) Systems-Mass Spectrometry (MSD)

Gas chromatography system-mass spectrometry are qualitative analyzes of volatile compounds in combustion gases, there is no method or standard that performs the test, it was proposed to use this technique because of the need to identify volatiles compounds and their characteristics of composition chemistry. The compounds were determined on a thermal desorption system model Unite 2 by Markes, a chromatograph instrument model 7890B GC system and spectrometer model 5977A MSD both of the Agilent technologies. For each sample, a metal cartridge containing Tenax was used, previously conditioned thermally at $300{ }^{\circ} \mathrm{C}$ for 30 minutes before being used. The dynamic tests were carried at $35^{\circ} \mathrm{C}$ to $310{ }^{\circ} \mathrm{C}$ of temperature with temperature ramps of $4{ }^{\circ} \mathrm{C}$ to $20^{\circ} \mathrm{C}$ per minute. The chromatographic separation of the compounds was in a capillary column of 30 meters $\times$ 250 micrometers $\times 0.25$ micrometers (Agilent $\mathrm{J} \& \mathrm{~W}$ HP-5 ms). The capillary column has excellent inertness for active compounds, including acidic and basic compounds, and improved signal-to-noise ratio for better sensitivity and mass spectral integrity. The analysis of volatile compounds lasted 34 minutes for the two samples characterized. Differences between them were the silica oxide nanoparticles and the FR

Table 1 Control polyurethane and polyurethane nanocomposites with silica nanoparticles results determined experimentally according to test ASTM D635.

\begin{tabular}{|c|c|c|c|c|}
\hline Sample & Time of burning & Smoke & Result & Standard \\
\hline Ctrl PUR 1 & $\begin{array}{l}\text { Before } \\
15 \text { seg }\end{array}$ & Less & Self extinguishing & Accepted \\
\hline Ctrl PUR 2 & $\begin{array}{l}\text { Before } \\
15 \text { seg }\end{array}$ & Less & Self extinguishing & Accepted \\
\hline Ctrl PUR 3 & $\begin{array}{l}\text { Before } \\
15 \text { seg }\end{array}$ & Little bit & Self extinguishing & Accepted \\
\hline FSi PUR 1 & $\begin{array}{l}\text { Before } \\
15 \text { seg }\end{array}$ & Much more & Self extinguishing & Accepted \\
\hline FSi PUR 2 & $\begin{array}{l}\text { Before } \\
15 \text { seg }\end{array}$ & Much more & Self extinguishing & Accepted \\
\hline FSi PUR 3 & $\begin{array}{l}\text { Before } \\
15 \text { seg }\end{array}$ & Less & Self extinguishing & Accepted \\
\hline
\end{tabular}

Crtl = Control polyurethane;

FSi = Polyurethane nanocomposites with $\mathrm{SiO}_{2}$. 


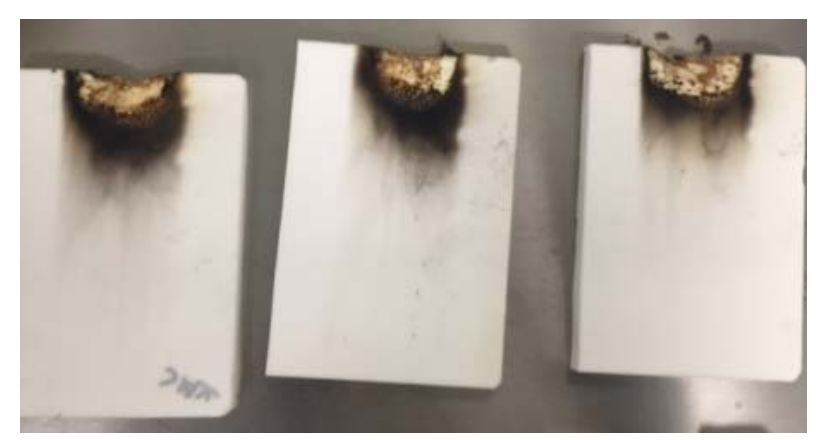

Fig. 5 Rigid polyurethane control after test ASTM D635.

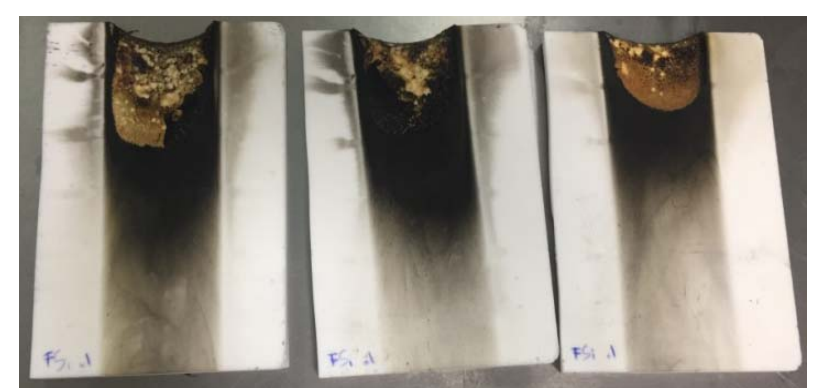

Fig. 6 Rigid polyurethane nanocomposite after test ASTM D635.

additive (Tris (2-chlorosopropyl) phosphate) for the nanocomposite polyurethane versus polyurethane reference.

In general, it was observed that the volatile compounds of the polyurethane and the polyurethane nanocomposites started at 2 minutes after test has initiated. The first component on polyurethane control to appear was the hexane at 2.154 minutes; it is not toxic because resulting with only $0.83 \%$ of degradation area. This material is used as foaming agent. However, hexane on PUNSi was detected at 2.15 minutes with $1.11 \%$ of degradation area. Other interesting material was the Benzene, it is an important organic chemical compound composed of six carbon atoms joined in a ring with one hydrogen atom attached to each. It is classify as hydrocarbon. This component is essential part of pre polymer MDI. However, it is a human carcinogen with degradation area of $18.77 \%$ on PUNSi, more than without FR and without nanoparticles obtained $1.44 \%$ of degradation area. On control sample at 23 minutes emerged tripropylene glycol with $16.59 \%$ of area but on safety data sheet is catalogued as not hazardous. Also derived from tripropylene glycol participated with $41.29 \%$ area for the total. In comparation to PUNSi tripropylene glycol, appeared at the same time, but with minus percentage only $2.23 \%$ of the total. It is surprising that after 28 minutes emerged Fyrol PCF FR additive (Tris (2-chlorosopropyl) phosphate) with $16.44 \%$ all these percentages are shown in Fig. 7. On the safety data sheet the supplier said that, when heated to decomposition, this chemical emits very toxic fumes. An advantage is that this material was produced before 28 minutes, on a fire situation the NFPA 1710 establish 240 seconds to arrive at fire area [41]. But in the case of extended time, you have less than this time to be rescued before starting to inhaled toxic gases compounded by chlorosopropyl phosphate. In future it is important to evaluate FRs completely free of halogenated organic additives for the plastic industry, combined with nanoparticles to reduce the quantity of them on the blend, and in turn the cost of polyurethane production.

On the other hand, a lot for components on gas chromatography (GC) systems and mass spectrometry (MSD) PUNSi could not be identified because probably the software does not have an updated bibliography. All components were graphed according to the minute that they were generated, observing 11 materials from 30 on the last in correlation.

Figs. 8 and 9 are plots of the compound abundance versus time of compound detection. Fig. 8 shows a reference sample (PU control), and the recorded peaks of volatile compounds. In general, it is observed that the volatile compounds of the polyurethane control had a lot for tripropylene glycol and derivatives. Chemical composition by mass spectrometry analysis for the polyurethane nanocomposite shows less styrene and the FR additive (Tris (2-chlorosopropyl) phosphate) at the ending of the thermal tests running.

Most of the halogen based compounds preferably work in the gas phase by acting as free radical scavengers and, in most of cases, were shown to be efficient for flame retardation [42-45]. As compared to 


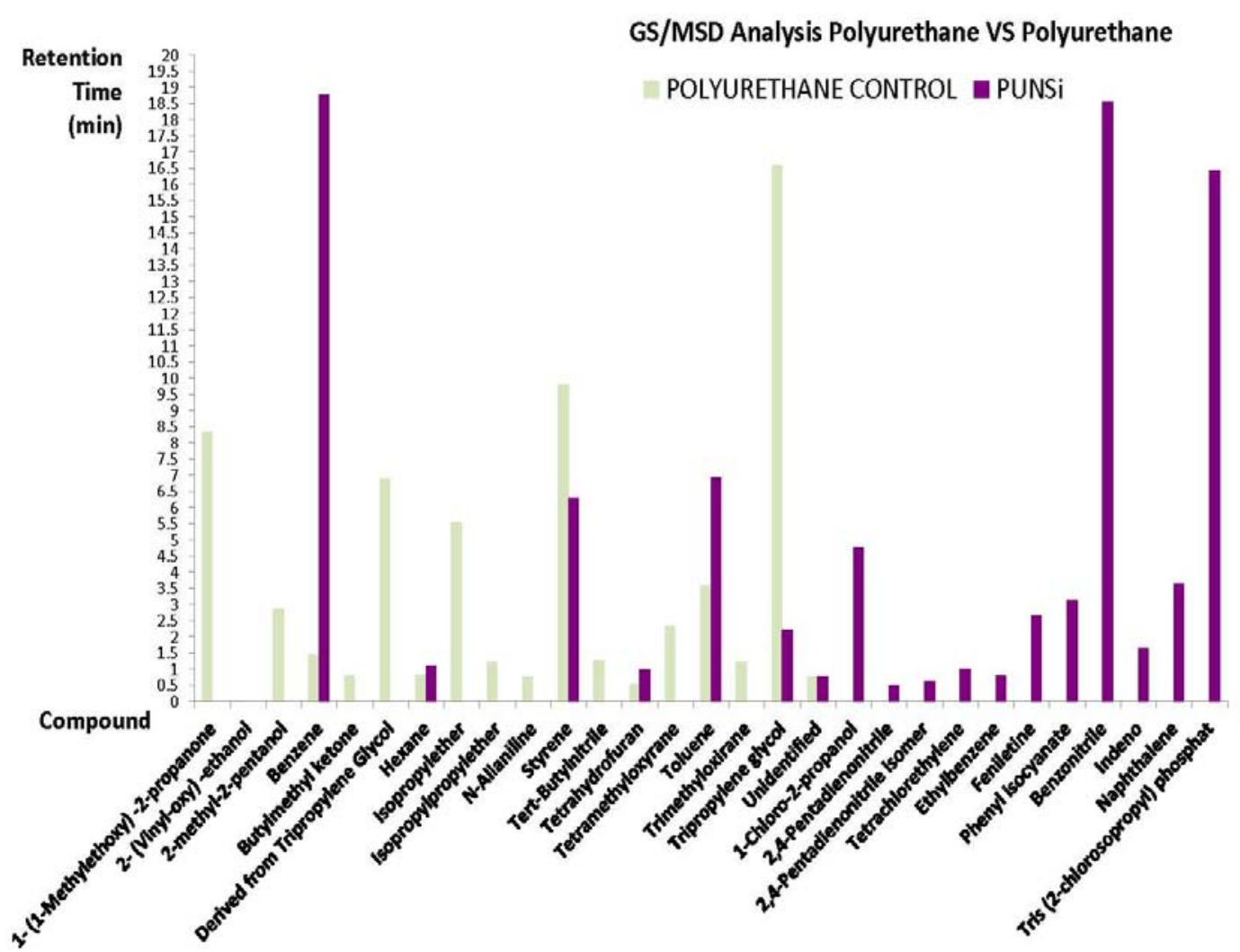

Fig. 7 GC/MDS analysis of polyurethane control and polyurethane nanocomposite with silica nanoparticles-FR.

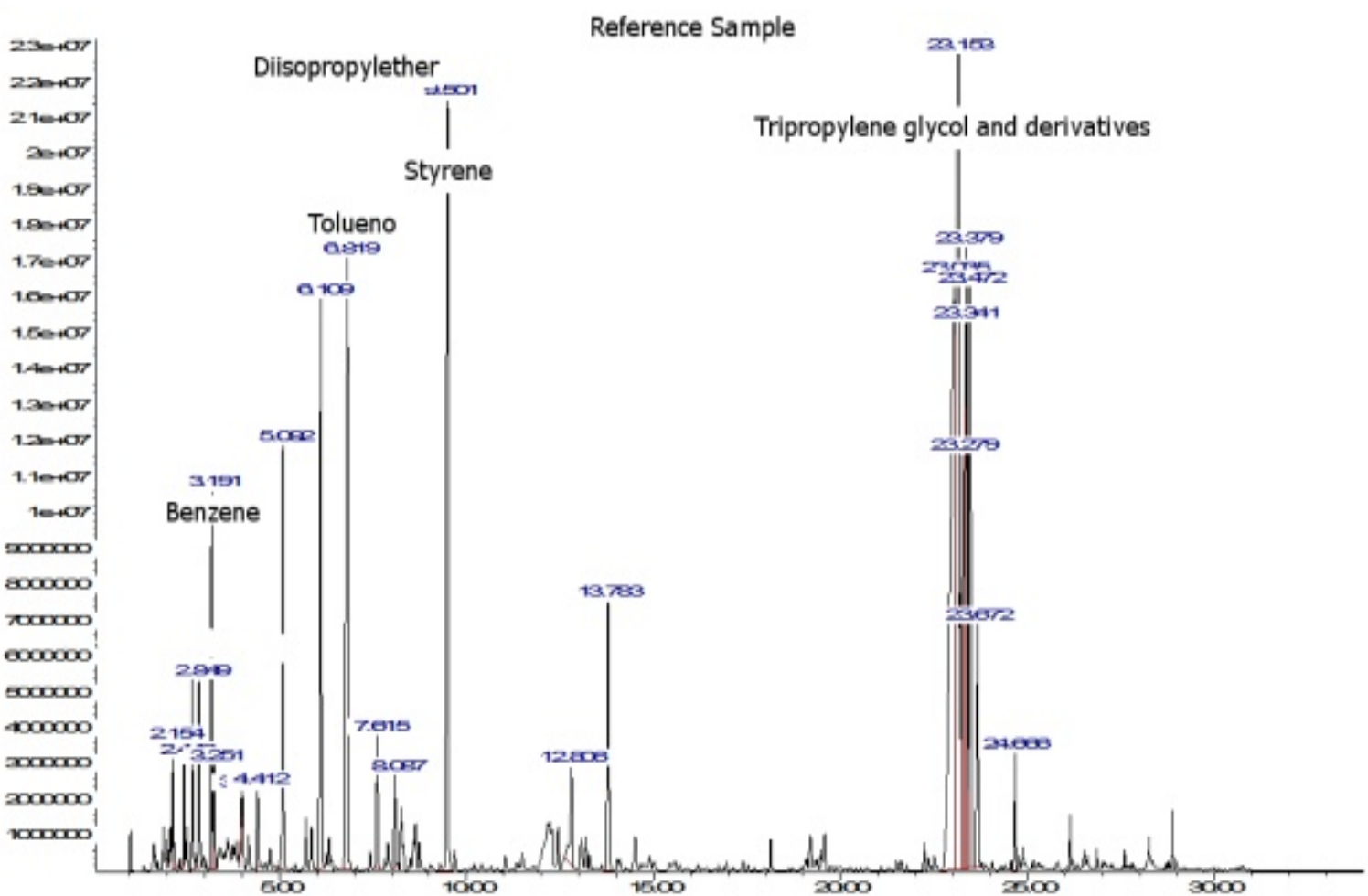

Tirre-

Fig. 8 GC/MSD analysis for polyurethane control. 

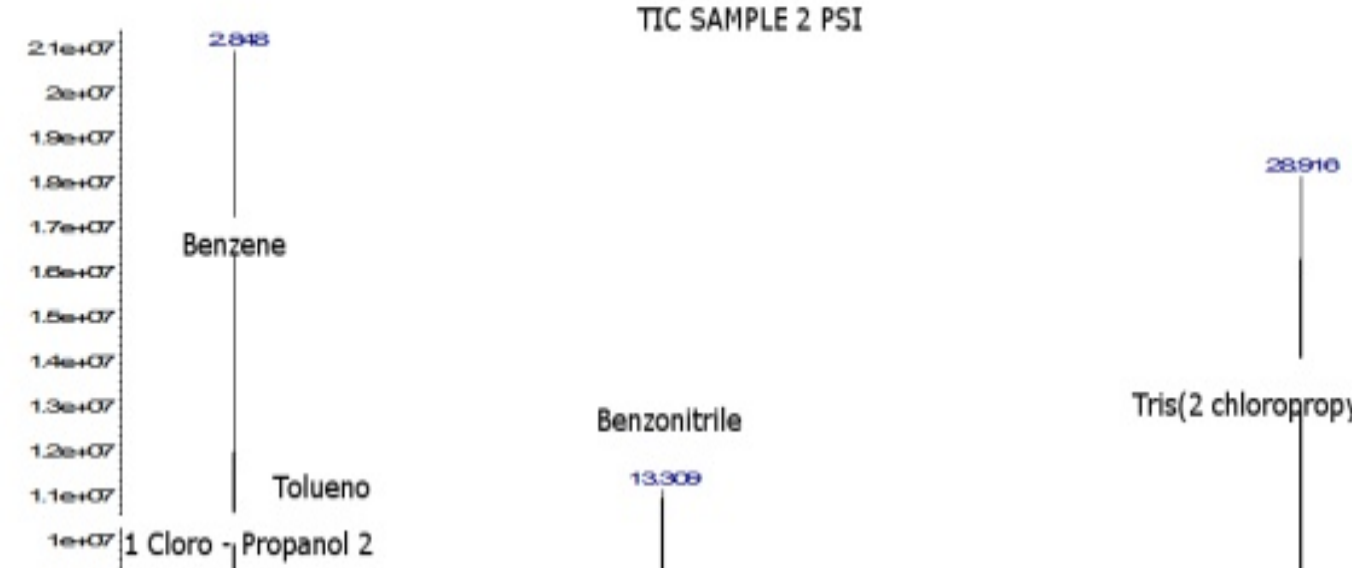

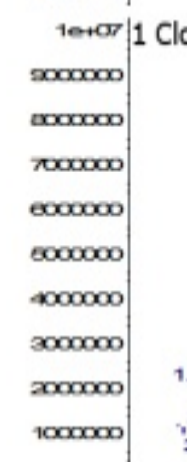

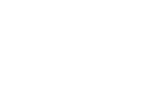

Benzonitrile

Tris(2 chloropropyl)phosphate
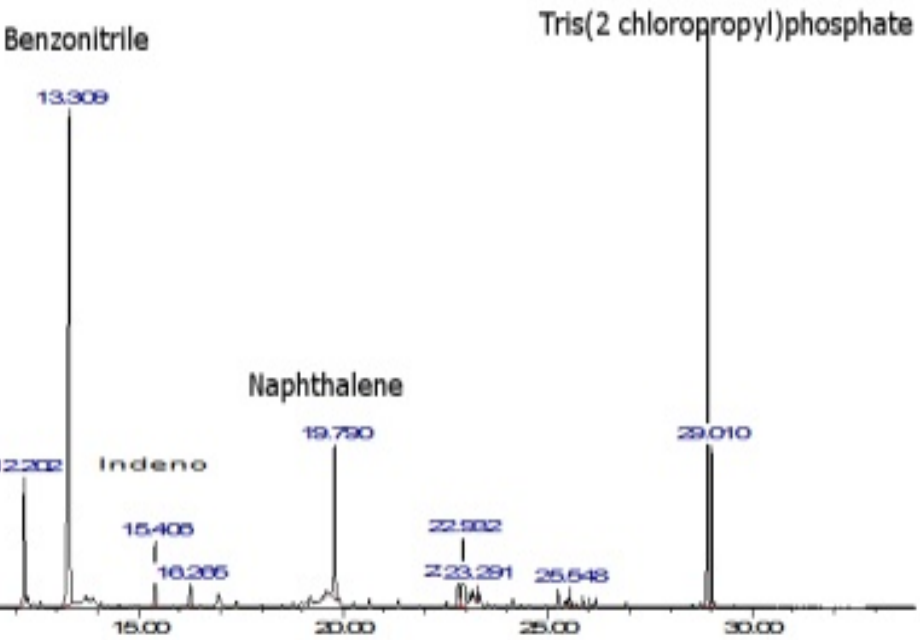

Tirre-

Fig. 9 GC/MSD analysis for polyurethane nanocomposites PUNSi.

other FRs, phosphorus FRs are also found to generate less toxic gases and smoke during combustion [46]. Polyether urethanes can easily experience thermal degradation at high temperatures, resulting in the oxidative cleavage of the polyether groups [47-49]. The thermal properties of the polymer nanocomposites are strongly dependent on the nanomaterial morphology in the polymer matrix [50].

According with Pumera [51], nanotoxicology has profound significance because the design and develop of nanomaterials used in industry and consumer products should be based on the result of such research as a priority. In this context, the mass analysis of the polyurethane nanocomposite looks to identify the nanoparticles volatiles on the combustion, as a result on silica oxide nanoparticles do not emerge.

\section{Conclusions}

The polyurethane nanocomposite for fireproof applications was evaluated and characterized with XDR, FTIR, SEM, GC/MSD and Atlas horizontal flame chamber equipment. The IR spectra provides information on the reactants, that is, the diisocyanate, diol and polyether glycol, and the ratio of the reactants used to prepare the polyurethane nanocomposite.

The sample of polyurethane with silica oxide nanoparticles produces more smoke and more combustion, but the advantage is that, there was less flame dripping with respect to the control sample. The results show that the incorporation of silica oxide nanoparticles into the polymeric matrix produces the self-extinguishing flame property in the composite material. Gas chromatography coupled system with thermal desorption analysis demonstrated that the additive Fyrol PCF in less quantity combined with dioxide of silica nanoparticles can improve some toxics gases depending the time of burning, however can provide security that the flame could retard during 
rescue time at an emergency.

The research of polyurethane nanocomposite could open new possibilities to resolve industrial problems. Therefore the development and innovation of polymers nanocomposite could help to save lives and to understand properties for new materials, for example: mechanical (modulus, impact strength), thermal properties (not melt or sag under normal use conditions) and flammability properties (meet regulations depending on the fire risk scenario).

At the end, It is important to improve and to develop products than can reduce fire events, first to avoid deaths, second to avoid injuries and finally not to have material and economic losses. Although there are regulations in favor of the health of the final consumer, industrialists avoid using FRs or new nanocomposites because the costs are too expensive. This research develops new polyurethane nanocomposites to bring a synergy between health and cost-effectiveness.

\section{Acknowledgments}

This investigation work was supported by the company development and finished on polyurethane (www.dapsapol.com) within their excellent initiative to development and innovate new technological material for new customer's requirements and to resolve industrial problems.

\section{References}

[1] Lu, S. Y., and Hamerton, I. 2002. "Recent Developments in the Chemistry of Halogen Free Flame Retardant Polymers." Progress in Polymer Science 27: 1661-712.

[2] U.S. Fire Administration. 2017. "U.S. Fire Statistics." http://www.usfa.fema.gov/data/statistics.

[3] Wu, D. H., Zhao, P. H., and Liu, Y. Q. 2013. "Flame Retardant Property of Novel Intumescent Flame Retardant Rigid Polyurethane Foams.” Polymer Engineering \& Science 53 (11): 247-85.

[4] Dueñas, A., Burillo, G., Alonso, J., et al. 2010. "Bases for the Clinical Management of Fire Smoke Poisoning." Emergencies: Journal of the Spanish Society of Emergency and Emergency Medicine 22 (5): 384-94.

[5] Pang, X. Y., Song, M. K., Tian, Y., and Duan, M. W. 2012. "Preparation of High Dilatability Expandable Graphite and Its Flame Retardancy for LLDPE.” Journal of the Chilean Chemical Society 57 (3): 1318-22.

[6] Huang, H., Tian, M., Liu, L., Liang, W., and Zhang, L. 2006. "Effect of Particle Size on Flame Retardancy of $\mathrm{Mg}(\mathrm{OH})_{2}$ Filled Ethylene Vinyl Acetate Copolymer Composites.” Journal of Applied Polymer Science 100: 4461-9.

[7] Du, L., Xu, G., Zhang, Y., Qian, J., and Chen, J. 2011. "Synthesis and Properties of a Novel Intumescent Flame Retardant (IFR) and Its Application in Halogen Free Flame Retardant Ethylene Propylene Diene Terpolymer (EPDM).” Polymer-Plastics Technology and Engineering 50: 372-8.

[8] Špírková, M., Pavlicevic', J., Strachota, A., Poreba, R., Bera, O., Kaprálková, L., et al. 2011. "Novel Polycarbonate Based Polyurethane Elastomers: Composition Property Relationship.” European Polymer Journal 47 (5): 959-72.

[9] Winey, K., and Vaia, R. 2007. "Polymer Nanocomposites.” Materials Research Society Bulletin, 32 (4): 314-22.

[10] Morgan, A. B., and Wilkie, C. A. 2007. "Practical Issues and Future Trends in Polymer Nanocomposite Flammability Research.” In Flame Retardant Polymer Nanocomposites, edited by Alexander, B., and Morgan Charles, A. Wiley, 355-99.

[11] Pholnak, C., Sirisathitkul, C., Soontaranon, S., and Rugmai, S. 2016. "UV-Vis Absorption and Small Angle X-Ray Scattering Spectra of Commercial Polyurethane Coating Filled with Zinc Oxide.” National Academy Science Letters 39 (2): 125-8.

[12] Zhai, W. T., and Park, C. B. 2011. "Effect of Nanoclay Addition on the Foaming Behavior of Linear PP-Based Soft TPO Foam Blown in Continuous Extrusion”. Polymer Engineering Science 51: 2387-97.

[13] Genovese, A., and Shanks, R. A. 2007 "Structural and Thermal Interpretation of the Synergy and Interactions between the Fire Retardants Magnesium Hydroxide and Zinc Borate.” Polymer Degradation and Stability 92 (1): 2-13.

[14] Antunes, M., Velasco, J. I., and Haurie, L. 2011. "Characterization of Highly Filled Magnesium Hydroxide-Polypropylene Composite Foams.” Journal of Cellular Plastics 47 (1): 17-30.

[15] Li, B., and Xu, M. J. 2006. "Effect of a Novel Charring Foaming Agent on Flame Retardancy and Thermal Degradation of Intumescent Flame Retardant Polypropylene.” Polymer Degradation and Stability 91: 1380-6.

[16] Morgan, A. B., Chu, L. L., and Harris, J. D. 2005. “A Flammability Performance Comparison between Synthetic and Natural Clays in Polystyrene Nanocomposites.” Fire and Materials 29: 213-29. 
[17] Zhang, S., and Horrocks, A. R. 2003. "A Review of Flame Retardant Polypropylene Fibres." Progress in Polymer Science 28 (11): 1517-38.

[18] Realinho, V., Haurie, L., Antunes, M., and Velasco, J. I. 2014. "Thermal Stability and Fire Behaviour of Flame Retardant High Density Rigid Foams Based on Hydromagnesite Filled Polypropylene Composites.” Composites Part B: Engineering 58: 553-8.

[19] Li, B., and Xu, M. J. 2006. "Effect of a Novel Charringefoaming Agent on Flame Retardancy and Thermal Degradation of Intumescent Flame Retardant Polypropylene.” Polymer Degradation and Stability 91: 1380-6.

[20] Ma, Z. L., Gao, J. G., and Bai, L. G. 2004. "Studies of Polypropylene-Intumescent Flame - Retardant Composites Based on Etched Polypropylene as a Coupling Agent.” Journal of Applied Polymer Science 92 (3): 1388-91.

[21] Kim, Y. S., and Davis, R. 2014. "Multi-walled Carbon Nanotube Layer-by-Layer Coatings with a Trilayer Structure to Reduce Foam Flammability." Thin Solid Films 550: 184-9.

[22] Mena, M. E., Torres, L. A., Gonzalez, J. L., and Mena, F. J. 2013. "Dielectric Protection Sole with High Shape Memory.” Mexican Patent WO2013012306.

[23] Wicklein, B., Kocjan, A., Salazar-Alvarez, G., Carosio, F., Camino, G., Antonietti, M., and Bergstrom, L. 2015. “Thermally Insulating and Fire-Retardant Lightweight Anisotropic Foams Based on Nanocellulose and Graphene Oxide.” Nature Nanotechnology 10 (3): 277-83.

[24] Pashaei, S., Siddaramaiah, and Syed, A. A. 2010. "Thermal Degradation Kinetics of Polyurethane/Organically Modified Montmorillonite Clay Nanocomposites by TGA.” Journal of Macromolecular Science, Part A-Chemistry 47 (8): 777-83.

[25] Wang, X. C., Geng, T., Han, J., Liu, C. T., Shen, C. Y., Turng, L. S., and Yang, H. E. 2017. "Effects of Nanoclays on the Thermal Stability and Flame Retardancy of Microcellular Thermoplastic Polyurethane Nanocomposites.” Polymer Composites, 1548-69.

[26] Sun, X. F., Kharbas, H., and Turng, L. S. 2015. "Fabrication of Highly Expanded Thermoplastic Polyurethane Foams Using Microcellular Injection Molding and gas-laden pellets.” Polymer Engineering and Science 55 (11): 2643-52.

[27] Wang, X. C., Jing, X., Peng, Y. Y., Ma, Z. K., Liu, C. T., Turng, L. S., and Shen, C. Y. 2016. "The Effect of Nanoclay on the Crystallization Behavior, Microcellular Structure, and Mechanical Properties of Thermoplastic Polyurethane Nanocomposite Foams.” Polymer Engineering and Science 56: 319-27.
[28] Yuan, M. J., Turng, L. S., Gong, S. Q., Caulfield, D., Hunt, C., and Spindler, R. 2004. "Study of Injection Molded Microcellular Polyamide-6 Nanocomposites.” Polymer Engineering and Science 44 (4): 673-86.

[29] Pearce, E. M., and Liepins, R. 1975. "Flame Retardants.” Environmental Health Perspectives 11: 59-69.

[30] Wang, Z., Han, E., and Ke, W. 2005. "Influence of Nano-LDHs on Char Formation and Fire-Resistant Properties of Flame-Retardant Coating." Progress in Organic Coatings 53: 29-37.

[31] Quede, A., Cardoso, J., Le Bras, M., Delobel, R., Goudmand, P., Dessaux, O., and Jama, C. 2002. "Thermal Stability and Flammability Studies of Coated Polymer Powders Using a Plasma Fluidized Bed Process.” Journal of Materials Science 37 (7): 1395-9.

[32] Liang, S., Neisius, M., and Gaan, S., 2013. "Recent Developments in Flame Retardant Polymeric Coatings.” Progress in Organic Coating 76 (11): 1642-65.

[33] Zhu, S. W., and Shi, W. F. 2002. "Flame Retardant Mechanism of Hyperbranched Polyurethane Acrylates Used for UV Curable Flame Retardant Coatings.” Polymer Degradation and Stability 75: 543-7.

[34] Hassan, M. A., Nour, M. A., Kamal, M. F., El-Marsafy, S. M., and Shaltout, I. M. A. 2012. "Effect of New Coating Flame Retardant System on the Flammability Properties of Different Building Materials.” Australian Journal of Basic and Applied Sciences 6 (3): 393-400.

[35] Hiltz, J., and Szabo, J. 2001. "FTIR Study of Poly(ether)urethanes.” Defense Research Establishment Atlantic.

[36] Pavlicevic, J., Špírková, M., Jovicic, M., Bera, O., Poreba, R., and Simendic, J. 2013. "The Structure and Thermal Properties of Novel Polyurethane/Organoclay Nanocomposites Obtained by Pre-polymerization.” Composites Part B: Engineering 45 (1): 232-8.

[37] ASTM D5132. 2011. "Standard Test Method for Horizontal Burning Rate of Polymeric Materials Used in Occupant Compartments of Motor Vehicles.” American Society for Testing and Materials.

[38] ASTM D4986. 2010. "Standard Test Method for Horizontal Burning Characteristics of Cellular Polymeric Materials.” American Society for Testing and Materials.

[39] ASTM D635. 2014. "Standard Test Method for Rate of Burning and/or Extent and Time of Burning of Plastics in a Horizontal Position.” American Society for Testing and Materials.

[40] ISO 3795. 2013. "Burning Behaviour of Interior Materials.” International Organization for Standardization.

[41] NFPA 1710. 2016. "Standard for the Organization and Deployment of Fire Suppression Operations, Emergency Medical Operations, and Special Operations to the Public 
by Career Fire Departments.” National Fire Protection Association.

[42] Troitzsch, J. H. 1998. "Overview of Flame Retardants: Fire and Fire Safety, Markets and Applications, Mode of Action and Main Families. Role in Fire Gases and Residues.” Chemistry Today 16: 18-24.

[43] Hacker, J. M., Kaufman, S., Sabia, R. A., Sauer, E. S., Tidd, J. C. E., and Walker, R. 1976. "Flame Retardant, Water Resistant Composition and Coating Transmission Member Therewith.” United States Patent US3944717.

[44] McKinney, J. M., and Hodson J. G. 1986. "Coated Fabric.” United States Patent US4594286.

[45] Dick, R. J., Mcginniss, V. D., and Rodgers, S. D. 1982. "Non-emissive, Flame-Retardant Coating Compositions." United States Patent US4557870A.

[46] Maiti, S., Banerjee, S., and Palit, S. K. 1993. "Phosphorus-Containing Polymers." Progress in Polymer Science 18: 227-61.

[47] Chattopadhyay, D. K., and Webster, D. C. 2009. "Thermal Stability and Flame Retardancy of
Polyurethanes." Progress in Polymer Science 34: 1068-133.

[48] Han, C. T., Chi, M., Zheng, Y. Y., Jiang, L. X., Xiong, C. D., and Zhang, L. F. 2013. "Mechanical Properties and Bioactivity of High-Performance Poly (Etheretherketone) Carbon Nanotubes/Bioactive Glass Biomaterials.” Journal Polymer Research 20 (8): 203.

[49] Gorghiu, L. M., Dumitrescu, C., Jipa, S., Olteanu, R. L., Zaharescu, T., Gigante, B., and Esteves, M. 2004. "Stable Oxidative Thermo-oxidant of LDPE Usanding New Synthesis Compounds of Secondary Aromatic Amine Class.” Materials Plastics 41: 66-9.

[50] Genovese, A., and Shanks, R. A. 2007. "Structural and Thermal Interpretation of the Synergy and Interactions between the Fire Retardants Magnesium hydroxide and Zinc Borate.” Polymer Degradation and Stability 92: 2-13.

[51] Pumera, M. 2011. "Nanotoxicology: The Molecular Science Point of View." Chemistry—An Asian Journal 6 (2): 340-8. 